
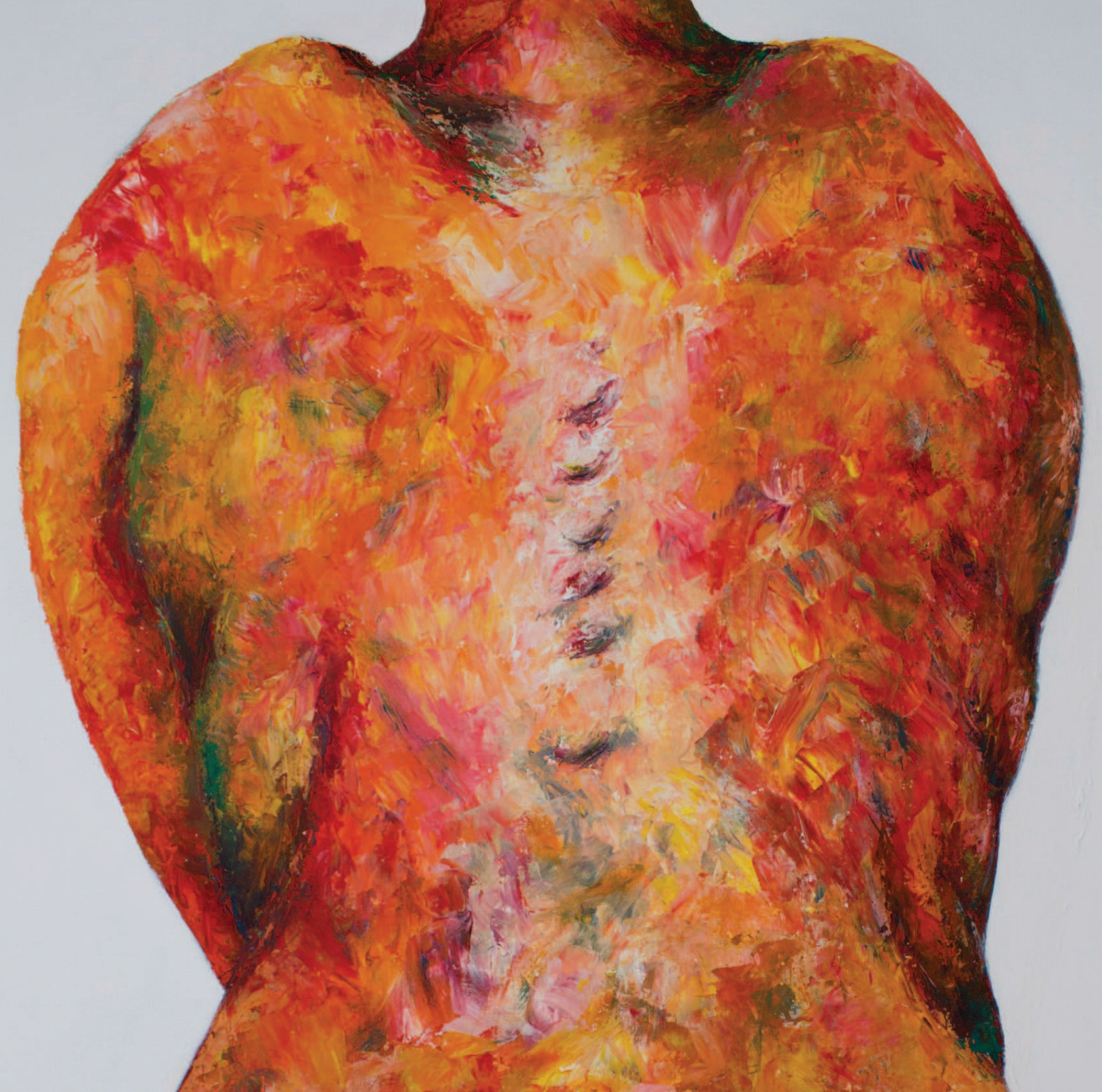

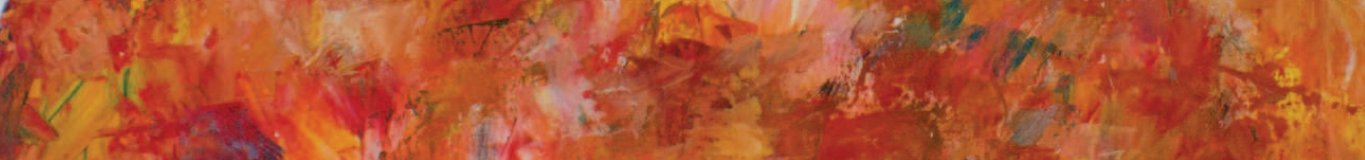

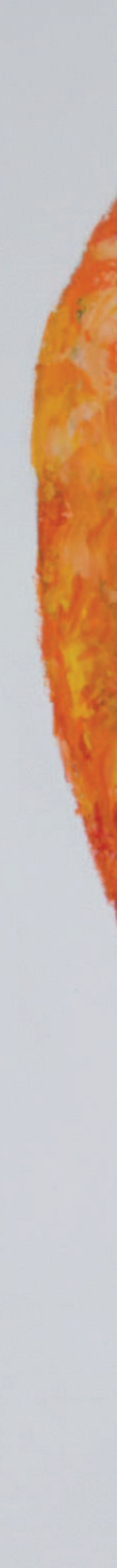

1

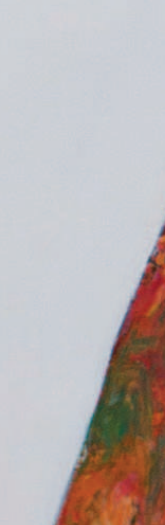

2.

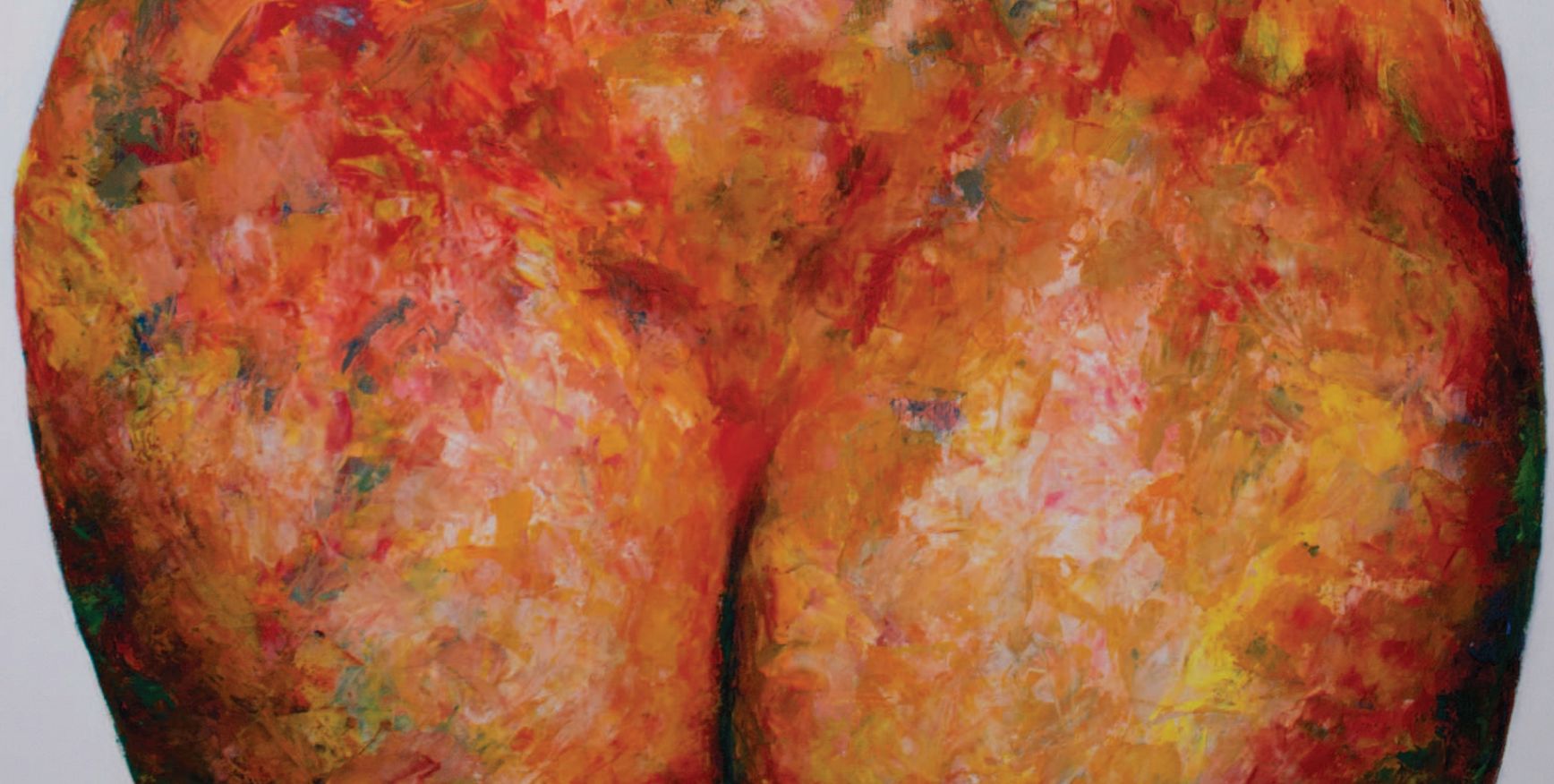




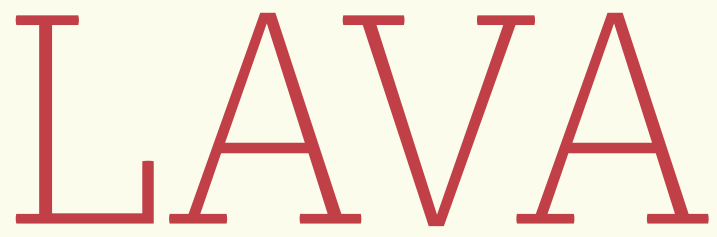

Matéria liquida lançada pelos vulcões.

Torrente, enxurrada, curso. 


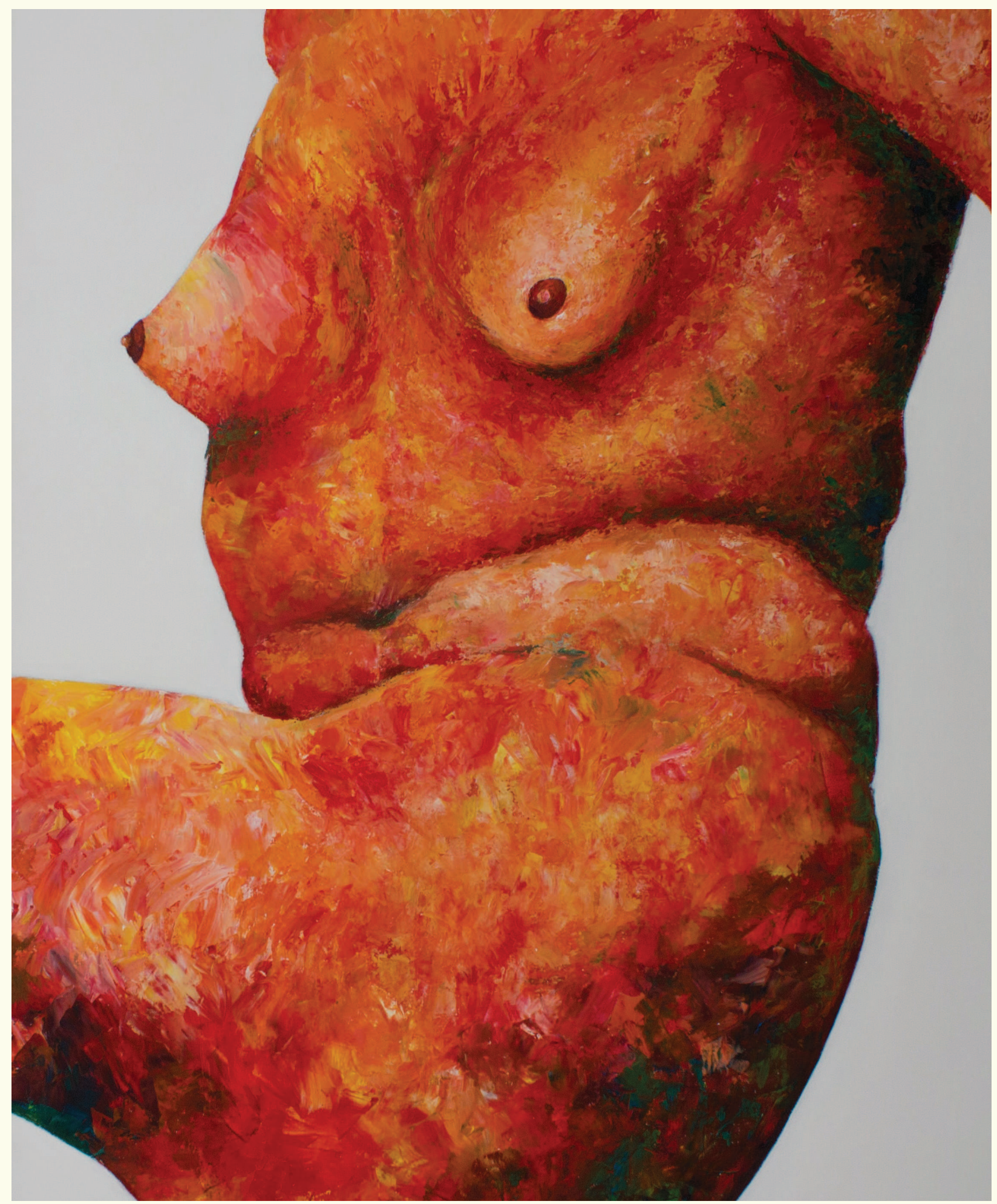

\section{POÉTICAS E POLÍTICAS DA VOZ}

Textos de conclusão do curso ministrado no segundo semestre de 2014 e indicados para publicação pelo Profo Roberto Zular. 


\title{
TÁCTICAS DE ESCUCHA DE WILLIAM BURROUGHS: TRANSMISIÓN — VIBRACIÓN — CONTRAPULSACIÓN
}

\author{
- JORGE MANZI
}

\section{RESUMEN}

Este escrito analiza el problema de la escucha en The Ticket that Exploded (1962/67), novela clave de la Trilogía Nova del escritor estadounidense William Burroughs. Luego de discutir el concepto psicoanalítico de la voz (en Mladen Dolar) en relación al diagnóstico adorniano de una regresión auditiva en la cultura de masas norteamericana, se presentará la particular aproximación de Burroughs a las tensiones propias de la acústica contemporánea. El objetivo principal del estudio consiste en ofrecer algunas pistas teóricas para entender el registro vibrátil de la escucha de Burroughs y la posibilidad que abre para nuevas tácticas defensivas del sujeto frente a circuitos audiovisuales administrados.

Palabras clave: William Burroughs; El Ticket que Explotó; voz; psicoanálisis

\section{ABSTRACT}

This article analyses the complexities of listening in The Ticket that Exploded (1962/67), the key novel of William Burroughs's Nova Trilogy. After discussing the connections between the psychoanalytical concept of the voice (in Mladen Dolar) and Adorno's thesis of a regression of listening in US mass culture, I will present Burroughs's particular approach to the tensions within contemporary acoustics. The main goal of this study is to offer a theoretical framework for understanding Burroughs's vibrating dimension of listening, and how it can enable new defensive tactics for subjects confronted to administered audiovisual circuits.

Keywords: William Burroughs; The Ticket That Exploded; voice; psychoanalysis 


\section{NOVA}

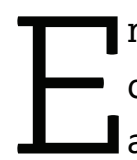

n "Sobre el carácter fetichista de la música y la regresión de la escucha" (1938), Theodor Adorno intentó una primera aproximación a la cultura de masas norteamericana, basándose en el diagnóstico de una "regresión de la escucha" generalizada. Su ensayo se centra en una crítica de la lógica y de los materiales propios del broadcasting, como estrategia para formular una nueva constelación de problemas ligados a la experiencia contemporánea: un modelo de memoria amenazado por la irrupción repetitiva de fragmentos radiales pregnantes; una producción fantasmática ligada al sadomasoquismo; una nueva indiferenciación entre deseo y adicción administrada; fenómenos de degradación ligados a la repetición de mensajes (AdoRno, 1991). En una escena clave de su ensayo, Adorno nos presenta un grupo de radioaficionados al jazz que en la época se hacían llamar jitterbugs, sin avergonzarse de "su transformación en escarabajos zumbando y girando en fascinación" ${ }^{\prime}$. Se reunían en clubes nocturnos, y poseídos por un "éxtasis sin contenido"2, como salvajes al ritmo de "tambores de guerra", improvisaban gestos rígidos que se asemejaban a "reflejos de animales mutilados" (p. 53). Sólo bailaban las "good parts": "[t]he same jitterbugs who behave as if they were electrified by syncopation dance almost exclusively the good rhythmic parts" (IDEM, ibid).

Adorno interpretó el baile del jitterbug como un intento sintomático de reaccionar al lugar pasivo propio de la radioescucha: la necesidad de salir afuera a sacudirse en jitters. ${ }^{4}$ Ciertamente estos movimientos espasmódicos eran reacciones crudas, simbólicamente poco elaboradas, pero al mismo tiempo revelaban con nitidez la irrupción de un nuevo registro vibrátil en la escucha contemporánea - un registro que aún no ha recibido suficiente atención. La regresión del oído acusada por Adorno, y radicalmente expresada por los jitterbugs, problematiza los intentos de circunscribir la audición exclusivamente al par resonancia-sentido, como Jean-Luc Nancy en su A la escucha, y exigiría considerar adicionalmente la relevancia que tendría para la audición contemporánea el par vibración-goce - un par que en principio no parece apuntar o conducir hacia el sentido, ni hacia una articulación simbólica satisfactoria.

En base a un análisis de la Trilogia Nova de William Burroughs, también conocida como Trilogia Cut-up, este estudio intentará apuntar a una serie de elementos que podrían ser relevantes para pensar el problema de la audición en contextos dominados por canales o circuitos audiovisuales opacos y administrados. Se trata de una problemática que está en el centro de las tres novelas que Burroughs escribió y re-escribió a lo largo de la década de 1960 - The Soft Machine (1961/1966/1968), The Ticket That Ex-
[1] " $[. .$.$] their transformation in$ beetles whirring around in fascination" (AdoRno, 1991, p. 53).

[2] "Their ecstasy is without content" (IDEM, ibid).

[3] "[...] like the ecstasies savages go into in beating the war-drums" (IDEM, ibid).

[4] En relación a la argumentación que se seguirá en este estudio, es interesante adelantar que la palabra jitter, referida originalmente a escalofríos y temblores ansiosos, fue luego utilizada como término técnico en el campo de la informática para referir a alteraciones abruptas e indeseadas en la transmisión de señales. 
ploded (1962/1967) y Nova Express (1964). La trilogía es, por una parte, un laboratorio destinado a consolidar una nueva técnica de montaje (conocida como "cut-up"), y por otra, un extravagante relato de ciencia ficción que confronta en un mismo plano de realidad a agentes humanos (la "Nova Police") y criminales virales (la "Nova Mob"), que diseñan tácticas para someterse unos a otros, sirviéndose de tecnologías que transmiten voces fálicas de mando, imágenes de sexo y dolor, en paralelo a vibraciones insectiles que paralizan a las víctimas en la medida en que las fuerzan al goce. Adoptando el punto de vista de quien se considera ya completamente inmerso en la problemática situación nova, Burroughs explorará la posibilidad de que la regresión auditiva criticada por Adorno no sea sólo la degradación de un modelo de escucha más ilustrado, sino al mismo tiempo parte esencial de una estrategia defensiva necesaria para reorganizar al sujeto contemporáneo. A lo largo de este estudio, se presentará la Trilogía Nova como un intento de atravesar la experiencia del jitterbug, sustituyendo espasmos fisiológicos por nuevas posibilidades de codificación simbólica para la literatura.

\section{VOCES PREGRABADAS}

La teoría psicoanalítica ha liderado una reconceptualización contemporánea de la voz y de la escucha que tal vez resulte pertinente considerar en el marco de la regresión auditiva diagnosticada por Adorno. En A voice and nothing more, Mladen Dolar describe al sujeto como un circuito que conecta boca y oreja, tras pasar por la circunvalación del Otro. Siguiendo la conocida fórmula de Lacan según la cual el sujeto recibe su propio mensaje invertido desde la instancia del Otro, Dolar propondrá que quien habla envía mensajes que retornan alterados como "voz". La voz no es aquello que sale de la boca ("speech") sino la resonancia que adquiere esa habla tras pasar por la compleja red del significante (DoLAR, 2006). La voz es un mensaje invertido o un re-envío que a su vez ofrece un acceso a los significantes que han determinado su recorrido - es decir, ofreciendo acceso a la textura significante del inconsciente. El trabajo de análisis, en donde la escucha del paciente es auxiliada por un analista, está orientado a alterar la voz, a modificar sus recorridos y, de ese modo, alterar el destino del sujeto. Enfrentar (y modificar) una voz exige ahora al menos dos pares de oídos - uno de ellos, el del analista, fuertemente entrenado. En definitiva, el psicoanálisis supone un sujeto que habla con gran facilidad (es sólo asociación libre) pero que en principio no sabe escucharse. En las antípodas de la tradición auto-reflexiva que caracterizó a la escritura moderna, en tiempos de regresión auditiva nadie parece querer quedar a solas con la propia voz. 
La argumentación de Dolar parece reformular el problema de la regresión auditiva de Adorno desde su reverso vocal: un nuevo objeto excesivo e inmanejable, la voz, es introducido en el circuito más íntimo y cotidiano del sujeto. Pero en lugar de historizar este movimiento, como lo intentó Adorno con la escucha, Dolar esencializa (o deshistoriza) el concepto de voz: toda voz es (y fue) siempre ajena y excesiva. (Para percibirlo bastaría entrenar suficientemente la escucha analítica). Si bien en Dolar la pregunta por la especificidad histórica de su objeto-voz queda en suspenso, es claro que su esfuerzo teórico participa de una tendencia contemporánea que expresa cierta urgencia relacionada a la crítica de voces excesivas que desestabilizan, someten y precarizan al sujeto: la amenaza de disolución gozosa en el llamado de las sirenas (en Kafka, Adorno, o en Jean-Michel Vivès); las voces subyugantes y radicalmente ajenas experimentadas en los rituales y en la mente primitiva (en los trabajos de Julian Jaynes o Eduardo Viveiros de Castro); la voz de Dios en el Antiguo Testamento (en Derrida o en Dolar); o bien, la voz tecnificada del amo contemporáneo en films como El Mago de Oz y El Testamento del Dr. Mabuse (retomada por críticos como Žižek, Michel Chion, y el mismo Dolar).

La obra de William Burroughs participa asimismo de esa tendencia general: su Trilogía Nova es una intensa exploración sobre voces excesivas y posibles tácticas de defensa auditiva, en muchos sentidos próxima a las pistas del psicoanálisis, pero en la que resulta imposible desligar la nueva situación acústica de sus condiciones históricas y tecnológicas. La obertura de The Ticket That Exploded deja en claro que la voz histriónica y espectacular del dictador de $\mathrm{Oz}$ ha quedado obsoleta, dando lugar a un movimiento más reciente de aplanamiento y uniformización de la voz de mando. La primera imagen vocal que nos ofrece Burroughs es la voz de B.J.: "that flat synthetic vulgar CIA voice of his" (BurRoughs, 2014, p. 2). Poco después el agente J. Lee, héroe de la novela, mantiene una entrevista con un Supervisor de Distrito, cuya voz es descrita como: "a voice without inflection, a voice no one could connect to the speaker or recognize on hearing it again" (p. 10). Lee comenta que al hablar de ese modo ciertamente el Supervisor había aprendido a manejar una "alien tool" (IDEM, ibid).

La misma voz plana, técnica e impersonal será usada indistintamente por el repertorio habitual de personajes de la trilogía: sargentos, psiquiatras, miembros de directorios de capital norteamericano, médicos militares, funcionarios y agentes. Voces unilaterales que dan órdenes y contra-órdenes, dictan instructivos y exigen sumisión. Todo el aparato de enunciación autoritario parece secuestrado por la misma voz. Incluso Dios tiene la garganta intervenida por una grabadora: "recorder music in the throat of God" (p. 151). Es una matriz estrictamente masculina de voz autoritaria ${ }^{5}$,

[5] La obra de Burroughs sostiene una exclusión radical de la voz femenina: no hay sirenas, ni madres, ni hermanas, ni siquiera funcionarias. 
una variación perversa de la matriz judeo-cristiana de la voz del padre, en donde la voz no está orientada a autorizar leyes futuras, a fundar una legalidad, sino que está allí simplemente para ofrecer su carácter excesivo al servicio de un texto ajeno, técnico y compulsivo que la antecede.

El modelo irreductible de esta vocalidad servil será lo que Burroughs define como "word": "the word is now a virus" (p. 56). La palabra como virus, quizás la fórmula más repetida en la obra del autor norteamericano, es un compuesto de vocalidad y repetición, en donde la voz es reducida a ser presencia que encubre una marca compulsiva cuyo objetivo es controlar el cuerpo humano. La vocalidad es esa parte esencial de la palabra que permite a la repetición vibrar junto a lo vivo. Para dar con la otra mitad habría que intentar ir más allá de esa presencia vocal, silenciarla, para encontrarse con el rumor de un texto ajeno y repetitivo que parece siempre imponer sus términos: "Modern man has lost the option of silence. Try halting your sub-vocal speech. Try to achieve even ten seconds of inner silence. You will encounter a resisting organism that forces you to talk. That organism is the word" (p. 56). Según Burroughs, desde que existen tecnologías de registro - desde que existe escritura no ha habido otra cosa que palabra viral, lo que conduce al autor a sus propias meditaciones bíblicas: "[i]n the beginning was the word and the word was bullshit” (p. 225).

A diferencia del modelo psicoanalítico de Dolar, la escritura de Burroughs no admite la posibilidad de un habla que no provenga desde un primer momento desde la alteridad (desde parlantes). En la Trilogía Nova no hay habla ("speech") sino sólo "voz" (como objeto, como re-envío). Toda vocalización ya ocurrió. The Ticket that Exploded presenta numerosos escenarios experimentales que llevan al límite su modelo de voz como retorno desde instancias técnicas. Uno de esos escenarios es una fiesta en donde cada invitado debe traer su propia grabadora portátil, y tiene estrictamente prohibido hablar: "no one can talk directly at a Carry Corder party" (p. 189). Todo lo que pretenda decirse debe ser grabado antes de llegar a la fiesta, y luego transmitido, mientras simultáneamente otros aparatos registran las transmisiones, editando y combinándolas con las voces de otros hablantes ausentes, dando lugar a una conversación que ocurre estrictamente entre máquinas. "There is no one there you got it? (p. 201) - el narrador de Burroughs suele interpelar en esos términos al lector, como quien sacude a un perro de su fascinación frente al gramófono. The Ticket that Exploded sugiere que frente a este particular tipo de circulaciones o circuitos de la voz, tal vez no resulte adecuado responder con la voz, es decir, añadir más voces u otras voces al circuito, cuando en definitiva "[n]o one is there to listen" (p. 202). 
La escena enunciativa elaborada por Burroughs es una transmisión incesante de voces de mando (tanto enemigas como aliadas), intercaladas con imágenes líricas, y breves enunciados narrativos al estilo "hard-boiled", que permiten una articulación mínima de la acción. En cuanto al registro vocal, se trata de un laberinto de voces fálicas pregrabadas en donde los orígenes de la enunciación se pierden desplazándose en "shifts" o cortes indicados por el signo mudo "--": "Gongs of violence show alternative answers to any question - Artists take over the entire answer battery of automatic junk state - I extended this to other flesh - Counterorders issued - Dictate force of riot police at the operation" (p. 194-5). El narrador de Burroughs se autodefine como "just a technical sergeant" (p. 193) frente a un conmutador ("switchboard") con inputs y outputs audiovisuales que re-envían una misma voz de mando plana y sintética. De modo que la narración es una transmisión de retornos vocales editados por un agente que se ha retirado después de dictar las órdenes pertinentes: "Won't be much left — i dictated the necessary orders on the air — with human nights - Voices came through channels" (p. 196). Con el circuito boca-oreja cortado - ese circuito mínimo de la subjetividad moderna ilustrada - el tipo de escucha que queda por entrenar es una desprovista de auto-afección y de auto-reflexividad: en la Trilogía Nova ninguna voz será retomada o reformulada, sino a lo sumo repetida, cortada o recombinada. La escucha de la propia voz es sustituida por un análisis estratégico de mensajes ajenos con objetivos de edición y retransmisión. Bajo las condiciones nova los agentes de Burroughs recomendarán suspender el oído vocal (entrenar una estrategia o "astucia" para desoír voces fálicas de mando, que en un mundo administrado han tomado el lugar de las sirenas), y por otra parte, ofrecerán pistas para una reorganización defensiva de la escucha en torno a nuevas frecuencias vibrátiles.

\section{ESCRITURA BLANDA}

La Trilogía Nova explora las formas de un nuevo tipo de escritura que Burroughs considera hegemónica en el ámbito de la audiovisualidad administrada, que no podría ser satisfactoriamente comprendida bajo el modelo clásico de escritura fonética. El nudo entre presencia vocal y marca repetitiva ya no tendrá como base material la página escrita, sino directamente la carne viva del organismo. Burroughs propone la palabra viral - un compuesto de presencia y repetición orientada a someter al organismo - como modelo básico para describir el tipo de discurso posibilitado por nuevas tecnologías audiovisuales como la radio, la televisión 
[6] La literatura de Burroughs funciona como un laboratorio que diseña y rediseña circuitos discursivos tecnológicamente posibles, de un modo que remite siempre a la tesis básica de la investigación de Friedrich Kittler: "[t]echnologically possible manipulations determine what in fact can become a discourse" (KITTLER, 1990: 232). El breve prefacio de The Ticket That Exploded refiere explícitamente a la importancia de las posibilidades técnicas abiertas por la grabadora portátil (comercializada por Philips a partir de los sesenta) como guía para entender la serie de fantasías tecno-discursivas exploradas a lo largo de la novela.

[7] "[...] association lines come alive in your flesh" (BURROUGHS, 2014, p. 206-7).

[8] En alemán, los términos equivalentes a catchphrase (stichwort) y a slogan (schlagwort) refieren literalmente a traumas de carácter mecánico (morder, acuchillar, golpear) en el campo de la información. La palabra en inglés catchphrase enfatiza por su parte la acción de atrapar (catch). Lo mismo broadcasting: cast refiere al acto de lanzar un anzuelo, de modo que broadcasting tendría el sentido de lanzar un anzuelo hacia el espacio amplio - esperando algún enganche. A medio camino entre el inglés y el alemán la escritura blanda parece ser una que al golpear captura, o bien, que golpea después de enganchar. Cuerpos enganchados a un hilo que toma la forma de flujos audiovisuales que proviene de canales de información. y la grabadora portátil. ${ }^{6} \mathrm{El}$ habla viral tomará la forma de canales que transmiten una audiovisualidad excesiva (palabras, sonidos e imágenes pregrabadas) que se inscribe como pistas ("tracks") en el cuerpo del receptor. El cuerpo es un "ticket" compuesto por cadenas asociativas ("association locks") que cobran vida en la carne. ${ }^{7}$

"'First we must write the ticket', said the guard (Sound of liquid typewriters plopping into gelatine) - " (BuRROUGHS, 2014, p. 24). El objetivo de la escritura blanda es administrar o controlar cuerpos entendidos como "thin transparent sheets on which is written the action from birth to death - Written on 'the soft typewriter' before birth — cold deck built in - The house know every card you will be dealt and how you will play all your cards" (p. 181). "The house", los responsables de la escritura del ticket, son directorios de corporaciones norteamericanas ("boards") que delegan la implementación técnica a sus aliados en el sector publicitario y mediático (Burroughs refiere siempre a Madison Avenue, Hollywood, Life, Fortune, Times). Uno de los supuestos históricos de la trilogía es la acumulación de la producción audiovisual propia del mismo tipo de conglomerados que Adorno y Horkheimer habían denunciado en Dialéctica de la Ilustración. Se trata de un "primer momento" (acumulativo) de escritura blanda que es al mismo tiempo, y en un sentido muy crudo, una administración audiovisual de lo vivo, en donde el flujo de transmisiones comenzará, discretamente, a pulsar en el cuerpo del consumidor.

A diferencia de la escritura fonética, las marcas de escritura blanda no pueden ser leídas serialmente, de izquierda a derecha, sino que aparecerán en irrupciones, repeticiones, pulsaciones. Allí donde algo pulsa algo ha sido escrito en la carne. Ya el enigmático instinto de muerte, elaborado por Freud en Más allá del principio del placer (1920), lidiaba con un fenómeno muy similar: ¿cómo es posible que ciertas palabras, imágenes y sonidos, sin ejercer una fuerza mecánica sobre lo vivo, sean capaces de marcar y traumatizar a permanencia? El enigma de una audiovisualidad excesiva capaz de producir marcas "blandas" en la memoria, cuyo retorno compulsivo provoca no sólo malestar subjetivo sino también daño orgánico crónico (sintomatología fisiológica). En una pista paralela, es posible sugerir que la industria radiofónica y publicitaria, un campo indispensable para entender las exploraciones formales de Burroughs, ya había elaborado sus propias formulaciones y técnicas para explotar económicamente la escritura de "marcas blandas": golpes y capturas producidas on the air desde canales audiovisuales: hit songs, slogans, catchphrases. ${ }^{8}$

El plan de William Burroughs en su Trilogía Nova consiste en aproximar las formas literarias tanto como sea posible a la lógica de la 
escritura blanda, tomando como modelo (y como competencia) tanto el broadcasting y la publicidad administrada, como otro tipo de materiales más duros como el porno y films de tortura - cuya "dureza" es proporcional a la facilidad o eficacia con la que logran inscribirse en el cuerpo del consumidor. Para Burroughs la urgencia radica en detectar la lógica de las nuevas unidades de escritura, el lugar en donde se cortan, y el modo en que se anudan. Y para ello buscará respuestas en el cruce entre teoría de información y fisiología, llegando a la siguiente fórmula elemental: trátese de imágenes, sonidos o palabras, la escritura blanda opera siempre en base a "sex and pain information" (p. 201). Aquello que es del orden de la presencia (audiovisualidad reproductible) opera como pantalla o captura imaginaria - a nivel de la conciencia - que encubre una inscripción subliminal, un golpe que ocurre en otro nivel: una zona de contacto-fusión entre lo simbólico y lo fisiológico (que a su vez vuelve inestable dicha distinción). ${ }^{9}$ Dar cuenta de marcas o unidades de escritura "blanda" que no son idénticas a la presencia audiovisual que las produce exige trabajar con conceptos "puros" de lo simbólico, es decir, conceptos de los simbólico formalmente distinguibles del nivel de la presencia: el concepto estricto de significante (una pura diferencia entre marcas presentes y ausentes) o el concepto moderno de información (una medida cuantitativa y probabilística del mensaje ${ }^{10}$ ). Pero Burroughs torcerá el proyecto "purista" de una teoría matemática de la información hacia sus puntos de contacto con el cuerpo humano: no se trata ya de la relación entre mensaje seleccionado y cantidad de información, sino entre información y fisiología. El tipo de información que le interesa no es apenas sobre sexo y dolor, sino que es sexo y dolor (adicción y trauma): un nivel en que carne e información pierden sus límites: "Film flesh" (BuRROughs, 2014, p. 79). Carne e información sincronizan sus pulsaciones y también sus degradaciones, lo que exigiría pensar en nuevos nudos entre entropía cibernética y entropía termodinámica.

Una teoría de la escritura blanda se enfrenta a considerables dificultades en su articulación conceptual. Y sin embargo Burroughs apostó a que se trata de un fenómeno a tal punto prosaico y constitutivo de la experiencia contemporánea que puede ser dado por supuesto: "You understand sex and pain information so why ask questions?" (p. 201). De hecho, la extravagancia de sus elaboraciones conceptuales y formales no impidió su masificación: el rostro de Burroughs quedó en el centro de la carátula del Sgt. Pepper's Lonely Hearts Clubs Band entre los íconos del siglo. La ciencia ficción de Trilogía Nova, que enfrenta en un mismo plano agentes virales y humanos, parece haberse tornado una suerte de realismo sórdido en lo que respecta al consumo prosaico de audiovi-
[9] Friedrich Kittler sostiene que los medios tecnológicos trabajan un tipo de relación con la fisiología del receptor que queda fuera del alcance de las mediaciones imaginarias (KITTLER, 1990). A determinada velocidad los cortes discretos de una cinta cinematográfica serán percibidos imaginariamente como continuos. Pero los cortes siguen allí, relacionándose con la fisiología en una zona inconsciente "where bodies and media technologies come into contact" (p. 238). Ese es precisamente el lugar "subliminal" de la escritura blanda.

[10] El concepto de entropía cibernética permite sintetizar la diferencia entre información y presencia: la repetición de un mensaje implica al mismo tiempo identidad a nivel de la presencia (mismas palabras, imágenes o sonidos) y una pérdida en el nivel de la información (el mensaje repetido se ha vuelto más probable, y por tanto menos informativo). 
[11] Al respecto, los paralelos entre la lógica viral de Burroughs y el modo en que Mladen Dolar describe la intrusión de la pulsión ("drive") en el organismo vivo son sistemáticos: "they [las pulsiones] behave like parasites which derail the organic from its natural course, but their parasitism takes support from an excess produced by the invasion of the symbolic into the body, the intrusion of the signifier into the corporeal. What does the net of signifiers, this abstract and negative differential matrix, and the body have in common? [...] their intersection is the drive, which does not simply pertain to either the signifier or the organic; it is placed at the point of their 'impossible' juncture" (DolaR, 2007, p.156) sualidad administrada y sus consecuencias. El enigma que Burroughs exploró estéticamente como escritura blanda y lógica viral parece tener una pretensión de objetividad análoga a la dimensión igualmente problemática que el psicoanálisis ha elaborado como "pulsión", en los mismos términos de no presencia, pulsación y de indiscernibilidad entre símbolo y cuerpo, entre lo inorgánico y lo orgánico (DoLAR, 2006). ${ }^{11}$

\section{REWRITE DEPARTMENT}

Si bien la Trilogía Nova tiene como programa aproximar la forma literaria a las lógicas nocivas de la escritura blanda, el objetivo no consiste en escribir nuevos "tickets" administrados, serviles a los conglomerados de capital y media, sino en hacer explotar los ya existentes. The Ticket That Exploded es el título de la novela más compleja y radical de la Trilogía Nova. Se trata de una guerrilla de inscripciones dirigida por un "Rewrite Department" contra los planes de escritura viral de los conglomerados hegemónicos, bajo la siguiente consigna: "[s]ubliminate the subliminators" (BuRROUGHS, 2014, p. 189). Los héroes de la novela son una serie de agentes encubiertos - liderados por el agente Lee - que viven bajo condiciones enemigas, entrenándose en el uso de armas virales alienígenas, a la espera del momento adecuado para entrar en acción. La operación exige reconocer, romper y recombinar las cadenas asociativas ya inscritas en los "tickets", es decir, en los cuerpos: re-escribirlas con al menos "ten alternative answers to any association locks" (p. 196).

Bradly, uno de los líderes de la Nova Mob (es decir, del bando viral enemigo), será la principal víctima de las operaciones de re-escritura de los agentes. The Ticket That Exploded está organizada como una sucesión de escenas en donde el "ticket" viral de Bradly es cortado y recombinado. La operación de re-escritura es un segundo momento de escritura blanda que tiene por objeto radicalizar la lógica nociva de la escritura viral hasta tornarla insostenible. La re-escritura del cuerpo de Bradly tomará la forma de una progresión de sesiones de tortura audiovisual, que comienzan con un despertar vibrátil de fantasías sexuales:

Bradly was in a delirium where any sex thought immediately took three-dimensional form through a maze of Turkish baths and sex cubicles fitted with hammocks and swings and mattresses vibrating to a shrill insect frequency that danced in nerves and teeth and bones - 'a thin singing shrillness that touched the nerves as well as the ears and made them vibrate ecstatically to the same beat' (p. 26). 
Todas las escenas de re-escritura estarán atravesadas por un tipo de vibración galvánica que difiere radicalmente de otros modelos más clásicos de vibración que suponen la posibilidad de un encuentro feliz con la alteridad (sea con la Naturaleza, con el o la amada, etc.). Aquí siempre se trata de vibraciones sintéticas manipuladas como un arma. ${ }^{12}$ Someten al sujeto a un goce administrado cuya función será precisamente abrir superficies de inscripción en la carne.

The room hummed and vibrated - Pubic hairs of black wire crackled in blue sparks and a quivering blue line divided his body — Bradly felt his own body split down the middle like a cracked egg the two halves rubbing against each other, held together by some sticky gelatinous substance that leaked out the crack and dripped into the obsidian platform where he stood (p. 101).

La vibración provoca la emergencia de una línea divisoria en el cuerpo, una abertura obscena y pulsante ofrecida a los agentes para ser re-escrita: allí laten las viejas marcas de escritura blanda a la espera de recombinaciones.

Este proceso recombinatorio es narrado frecuentemente en The Ticket That Exploded como la entrada del sujeto a un parque de diversiones vibrátil llamado "Garden of Delights", imagen de una nueva alteridad a la vez sintética y trascendente, cuyas siglas son "G.O.D.". $\mathrm{El}$ ingreso está marcado por un fuerte enganche entre circuito y cuerpo: "you sit down anywhere some sex wheel sidles up your ass or clamps onto your spine centers" (p. 3-4). Es el inicio de un recorrido veloz de desposesión subjetiva en donde las palabras, imágenes y ruidos íntimos de la víctima son primero grabados y luego recombinados con pistas audiovisuales de cuerpos ajenos (de otras víctimas o de agentes entrenados), así como con líneas asociativas ya existentes (viejas hit songs, slogans, catchphrases). Si el primer momento (acumulativo) de escritura blanda obedecía al modelo del broadcasting centralizado, este segundo momento subversivo de grabaciones, recortes y recombinaciones, supone las posibilidades técnicas abiertas por nuevos aparatos descentralizados, como la grabadora portátil: "It's all done with tape recorders" (p. 184). ${ }^{13} \mathrm{~A}$ la salida de este Jardín de las Delicias están los cuerpos de las víctimas colgados y drenados de toda identidad subjetiva: "muttering absent bodies hanged after being milked of identities" ( $p$. 115). Tras las operaciones de re-escritura o re-combinación, un agente le pregunta a Bradly, con el característico humor negro de Burroughs: "And now how are we? —" (p. 82).
[12] Los agentes del Departamento Re-write manejan una "vibrating camera gun" (p. 174), que transmite imágenes a la vez que produce vibraciones en el receptor. Por su parte, los criminales nova siguen el mismo mecanismo básico, pero con sus propios diseños: "They can turn on total pain of the Ovens - This is done by film and brain wave recording mangled down to a form of concrete music - A twanging sound very much like positive feedback correlated with the Blazing Photo from Hiroshima and Nagasaki They can switch on electric pleasure leading to death in orgasm [...] They can alternate pain and pleasure at supersonic speed $[\ldots] "(p .125)$.

[13] De hecho una de las variaciones del Jardín de las Delicias, llamada "The Exhibition", tendrá por escenario el interior de una grabadora portátil, con paredes metálicas que pasan por momentos de magnetización (registro) y desmagnetización (borradura), produciendo una caída constante de polvo de palabra e imagen (p. 70). 


\section{TÁCTICAS DE ESCUCHA}

[14] La estática o white noise es un rumor de mayor o menor intensidad que revela la existencia cruda de canales de información. La producción de estática es tan inevitable para el circuito como la producción de ruidos para un cuerpo: "Technological media operate against a background of noise because their data travel along physical channels" (KITTLER, 1991, p.45). Toda administración audiovisual intentará mantener la estática en niveles mínimos (signal to noise rate), pero el rumor siempre persiste.
El único modo de desengancharse de los recorridos vibrátiles de desposesión será mediante otras vibraciones. La estática ("white noise"14) será el modelo de una contra-vibración capaz de producir un corte seco en la escritura blanda administrada. Los agentes de la Policía Nova la utilizan como un arma: "cutting virus troops with static noises" (p. 120). Por otra parte, la escucha de estática tendrá para Burroughs una significación que parece trascender la trama sci-fi de la Trilogía Nova, sugiriendo que podría tratarse de una experiencia capaz de producir transformaciones de fondo para la literatura. Una de las escenas más cuidadas de The Ticket That Exploded, trabajada con variaciones hacia el medio y el final de la novela, elabora una reminiscencia juvenil en la ciudad de Saint Louis (ciudad natal del autor). Bill - un aspirante a escritor - lee cuentos de Scott Fitzgerald mientras John intenta reparar una radio de cristal para que ambos puedan escuchar la señal. Al finalizar, John le pone los audífonos a Bill: "All right now . . his master's voice . . listen ..” (p. 212). Pero Bill sólo consigue escuchar estática: "the tinkling metal music of space" (p. 128). O en una variante, Bill escucha lo siguiente: "The sound was scarcely recognizable as human voices . . a cadence of vibration . . Bill felt a rush of vertigo as if the sofa was spinning away into space" (p. 212). En la trilogía no se reconsideran ni reformulan voces, pero con frecuencia se re-escuchan y analizan vibraciones. Bill retoma una última vez su escucha de estática y le comenta a John: "[t]hat static gave me a hard-on like something touched me" (p. 131). En definitiva, la escucha de ruido blanco funciona como una especie de "iluminación acústica", un momento clave en la formación del escritor contemporáneo, que podría ser descompuesto en tres momentos: en primer lugar, la estática ofrece un contacto real o "toque" con el circuito (audición del rumor físico de canales de información), el modo en que el contacto físico entre circuito y cuerpo se vuelve accesible a la conciencia; en segundo lugar, el ruido blanco permite un desenganche (una interferencia que impide o interrumpe la captura imaginaria en la transmisión audiovisual); y, como detalle final, una erección queda pulsando como una alerta, lo que nos exige retornar una vez más sobre el problema de la vibración, la pulsación y el goce incierto asociado al circuito.

The Ticket That Exploded es una larga exploración en torno a los nuevos registros y exigencias de escucha para un sujeto que está siempre ya integrado al circuito macabro del Jardín de las Delicias (G.O.D.). El oído está obligado a adaptarse porque en la trilogía de Burroughs no existe un espacio no integrado al circuito, y la única salida concebible exige tácticas de fuga auditiva a través de los canales. El nuevo registro 
vibrátil, en el que se insiste en cada una de las escenas de re-escritura blanda, aparece a la vez como amenaza de disolución subjetiva (por medio del goce) y como única orientación posible en medio de laberintos audiovisuales administrados. La vibración aparece como figura prioritaria para Burroughs en la medida en que ofrece un modelo de contacto (primordialmente auditivo) entre cuerpo y alteridad administrada, que en principio relega la conciencia a un lugar secundario, cuando no nulo.

La particularidad del registro vibrátil de Burroughs tal vez sea mejor comprendida en oposición al concepto de resonancia que Jean-Luc Nancy elabora en $A$ la escucha. Nancy concibe la resonancia como un tipo de vibración auditiva que se constituye en y por la diferencia de sentido, suponiendo a su vez un "escuchador" auto-reflexivo, siempre inclinado a alcanzar una significación (NANCY, 2014). ${ }^{15}$ La defensa y celebración de Nancy de un sujeto que permanece "a la escucha" implica un tipo de confianza en la vibración - como esencialmente orientada al sentido - altamente desaconsejable en el campo acústico propio de la Trilogía Nova. Y sin embargo Burroughs parece exigir a sus héroes que persistan, a pesar de las condiciones adversas, en una disposición auditiva radical. Se trata de una posición sostenible únicamente en la medida en que, mediante un apropiado entrenamiento, consigan dividir la escucha: suspender la escucha vocal-resonante (evitar toda captura imaginaria en el sentido) y elaborar un tipo de escucha no fonológica (es decir, no orientada a la diferencia de sentido): un oído-antena - y aquí volvemos al terreno del jitterbug - capaz de sintonizar variaciones de frecuencias sin sentido, a la espera de una pulsación. Porque si en la resonancia de Nancy algo siempre termina por hacer sentido, en la escucha vibrátil de Burroughs algo terminará por pulsar. Resulta fundamental entender que en el campo vibrátil de Burroughs la pulsación se sitúa en el lugar que le corresponde al sentido en el campo de la resonancia. Sentido y pulsación están en relación de homología en dos campos diferenciados de la escucha contemporánea: el registro resonante y el registro vibrátil. Ambos registros exigen una tarea de decodificación que obedece a lógicas diferentes.

La pulsación permite a los agentes de Burroughs detectar las huellas de la escritura blanda administrada, los cortes, el lugar de posibles re-combinaciones o re-escrituras. Para intervenir y alterar las pistas administradas, para mapear los puntos en donde es posible cortar, es necesario atravesar el Jardín de las Delicias intentando no disolverse en el goce de repetición: "Important thing is always courage to pass without stopping" (p. 136), “[...] without doing pictures" (p. 179); “[...] without doing things" (p.177). En otras palabras, diferir de los jitterbugs de Adorno: no entrar en goce con el circuito - evitar bailar las "good parts". Para atravesar
[15] Incluyo un pasaje extendido en el que puede percibirse el modo esencialmente auto-reflexivo y teleológicaente semántico en que Nancy entiende el problema de la escucha y de la resonancia: "Teríamos assim estabelecido que a escuta (se) abre à ressonância (se) abre ao si: ou seja, que ela abre ao mesmo tempo a si (ao corpo ressoante, à sua vibração) e ao si (ao ser enquanto o seu ser se põe em jogo por si mesmo). Ora, um pôr em jogo, quer dizer, o reenvio de uma presença a outra coisa que não ela mesma, ou a uma ausência de coisa, o reenvio de um aqui a um algures, de um dado a um dom, e sempre, a qualquer respeito, de alguma coisa a nada (à res do 'nada'), chama-se a isso o sentido, ou sentido" (46). "O escutador (se é que posso chamá-lo assim) está, então, assim inclinado a acabar pelo sentido [...] ou, então, está oferecido, exposto ao sentido" (p. 46). 
G.O.D. los guías de Burroughs se orientan por el oído: "The guide moved on music currents waiting for the beats and chords that lifted them up ladders and ramps, swept them along perilous platforms over voids of billowing heat - 'you learn quick, Meester - Music talk — In here'” (p. 142-43). Una música enrarecida que indica, por medio de pulsos, el lugar de los cortes discretos y binarios que interesan a los agentes del Departamento de re-escritura: "patterns pulsing to metal music, off on, on off" ( $p$. 70). En definitiva, la escucha vibrátil - una vez que el agente ha logrado atravesar G.O.D. sin disolverse - permite anticiparse estratégicamente a la pulsación: "I discovered that I could anticipate encounter" (p. 200). Y es allí donde la intervención cut-up debe ofrecer al menos "ten alternative answers to any association locks" (p. 196), liberando al sujeto de los peligros disolutivos del circuito administrado de mensajes compulsivos.

Para cerrar este argumento, es necesario enfatizar que el recorrido vibrátil de Burroughs no sólo está representado en el plano de la ficción, por medio de las grotescas imágenes de G.O.D., sino que está sistemáticamente expresado en la forma de la escritura literaria. A diferencia de la escucha vibrátil del jitterbug, orientada hacia una respuesta que acaba en sacudida fisiológica, las tácticas de escucha de Burroughs, si bien suponen una experiencia corporal intensa (capaz de sustentar una lectura pulsional), en última instancia apuntan hacia la elaboración de una respuesta o reacción simbólicamente codificada. La contra-pulsación en la que se basa la escritura cut-up de Burroughs es codificada en la forma literaria como contra-puntuación. En la Trilogía Nova los signos de puntuación convencional han sido sustituidos por un set basado en los pulsos mínimos y bélicos del código morse: guiones largos "—”, puntos suspensivos dobles ". ." y dobles puntos duplicados “::". En palabras del autor: "like morse code with scales of intensity and speed" (BurRoughs, apud. HarRIS, p. xliv). Una puntuación distintiva que comunica al lector - como pequeñas cicatrices - los lugares de corte y recombinación táctica de la escritura blanda. Son marcas afónicas pero aún simbólicas - que se despliegan a lo largo del texto como huellas de un ejercicio auditivo en fuga o contrapunto frente a la escritura viral. I 


\section{BIBLIOGRAFIA}

ADORNO, Theodor. "On the fetish character in music and the regression of listening". In The Culture Industry. Selected essays on mass culture. Ed. J.M.

Bernstein. London: Routledge, 1991.

BURROUGHS, William S. The Ticket That Exploded. The Restored Text. Ed. Oliver Harris. New York: Groove Press, 2014.

DOLAR, Mladen. A voice and nothing more. Cambridge: MIT Press, 2006.

HARRIS, Oliver. "Introduction”. In The Ticket That Exploded. The Restored Text. Ed. Oliver Harris. New York: Groove Press, 2014.

KITTLER, Friedrich. Discourse Networks 1800/1900. Stanford: Stanford University Press, 1990.

KITTLER, Friedrich. Gramophone, Film, Typewriter. Stanford: Stanford University Press, 1999.

NANCY, Jean-Luc. À escuta. Belo Horizonte: Edições Chão da Feira, 2014. 